\title{
HYGROTHERMAL ASSESSMENT OF ROOFS WITH ABOVE-RAFTER THERMAL INSULATION IN THE DETAIL OF THE EAVE OVERHANG
}

\author{
PAVEL SOUDEK ${ }^{1, *}$, LUBOR KALOUSEK ${ }^{1}$, ANTONÍN ŽÁK ${ }^{2}$ \\ ${ }^{1}$ Faculty of Civil Engineering, Institute of Building Structures, Brno University of Technology, \\ Veveř́ 95, 60200 Brno, Czech Republic \\ ${ }^{2}$ Stavebniny DEK a.s., Tiskařská 10/257, 10800 Praha 10, Czech Republic \\ *E-mail: soudek.p@fce.vutbr.cz
}

\begin{abstract}
This paper is focused on hygrothermal assessment of the eave overhang detail in above-rafter placed thermal insulation roof system. Results of the long-term measurement of this detail performed on a real building as well as the testing of the measuring method are presented in this paper. Within this measurement the moisture of wooden elements performing an eave overhang of the roof was monitored primarily in order to verify their long-term functionality. In addition the temperature and relative humidity in the roof structure were measured as well. As part of this measurement, various design variants of above mentioned detail in combination with different compositions of the roof structure were compared. The long-term functionality of the assessed details is evaluated in the conclusion of this paper, taking into account especially hygrothermal status of wooden element, which is associated with threats of infestation of these elements by wood decaying fungi or insects.
\end{abstract}

Keywords: wood moisture measurement, electrical resistance method, roofs with above rafter placed thermal insulation, eave overhang detail

\section{Introduction}

Above-rafter thermal insulation roofs system brings many undisputable benefits, e.g. more reliable application of the vapour barrier applied to the rigid wooden formwork. In addition, the bitumen sheets can be used as the vapour barrier, which are mechanically more durable than lightweight PE membranes. In such applications, there is a high probability of achieving both proper vapour and air tightness.

Another benefit is position of the rafters in the indoor climate, where there are stable conditions and therefore no threat of infestation by wood decaying fungi or insects.

Frequently discussed details of the system are roof overhangs, which are usually created by wooden elements anchored to the rafters. These wooden elements are placed in the roof composition between vapour barrier and underlay. The basic principles of structural timber protection are not met and therefore there is a high risk of the moisture content of these elements be- ing increased, and the associated risk of the attack by wood decaying fungi and insects can occur. These are the reasons why this detail was subjected to testing and the moisture content of these wooden elements was measured on a real-scale experiment. Several design variants of this detail were compared in different roof structures. The results of the two most frequently executed variants are presented in this paper. Also electricity resistance method accuracy and principles of probes installation are mentioned in this paper.

\section{Materials and methods}

\subsection{Moister content determining}

Wood moisture content can be measured by several methods. The electric resistance method is the most popular and also the most suitable for long-term measuring of wood moisture content. The relationship between electric resistance and moisture is shown in Fig. 1.

This is an open-access article distributed under the terms of the Creative Commons Attribution-NonCommercial 4.0 International License (https://creativecommons.org/licenses/by-nc/4.0/), which permits unrestricted use, distribution, and reproduction in any medium for non-commercial purposes, provided the original author and source are credited, a link to the CC License is provided, and changes - if any - are indicated. 


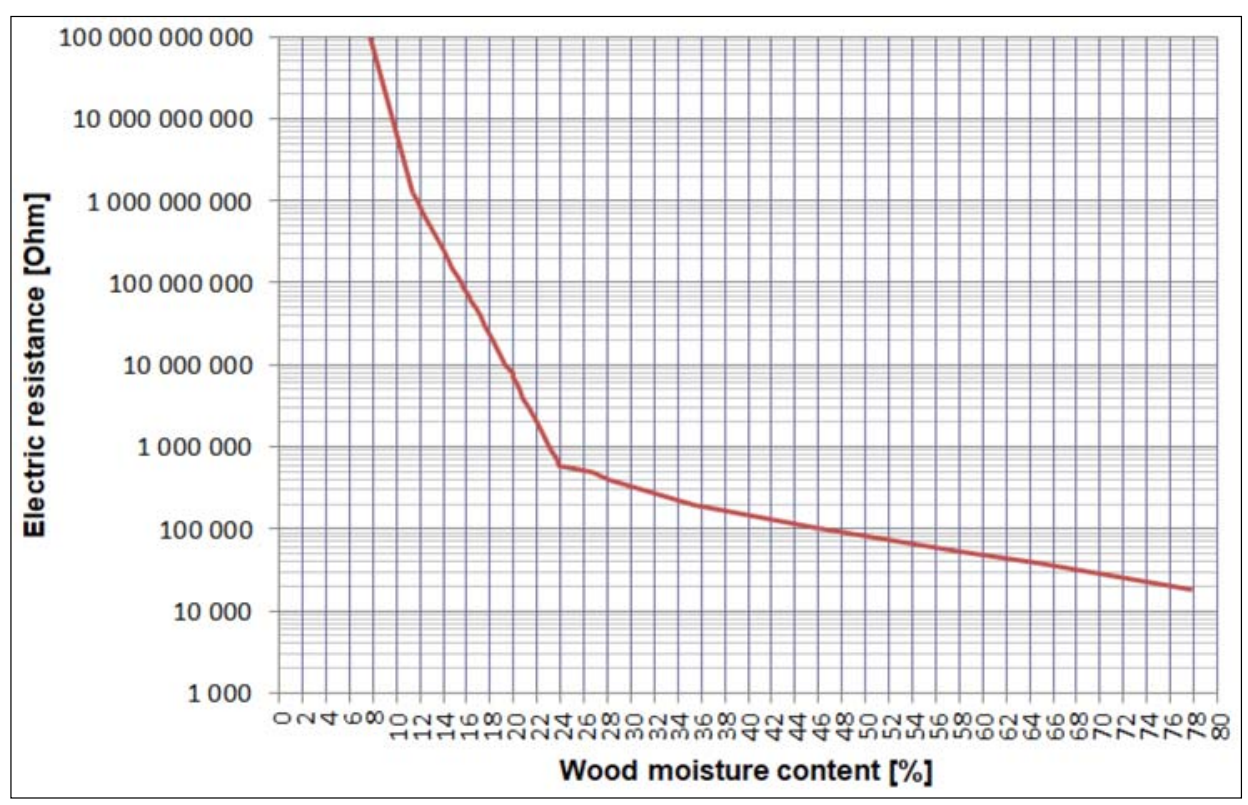

Fig. 1. The relationship between electric resistance and moisture content

Factors influencing the measurement by using resistance method as species of measured wood, temperature, grain direction, etc. are described e.g. in [1]. During long-term measurement it is also important to ensure a sustainable mechanical adhesion to the wood cells. Electrodes may not maintain a perfect electric contact due to the swelling and shrinking of wood. A higher resistance is measured because of the decreased contact between the electrodes and wood $[2,3]$. Therefore, electrically conductive glue was used to ensure stable connection between probes and wood cells. Electrically conductive Wire glue AP made by Anders products company was used for this purpose.

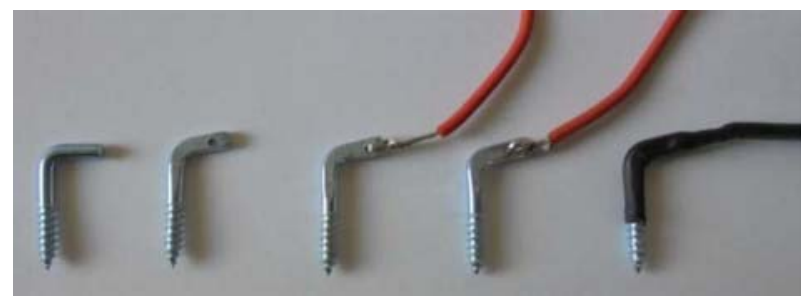

Fig. 2. Manufacturing process of surface probes

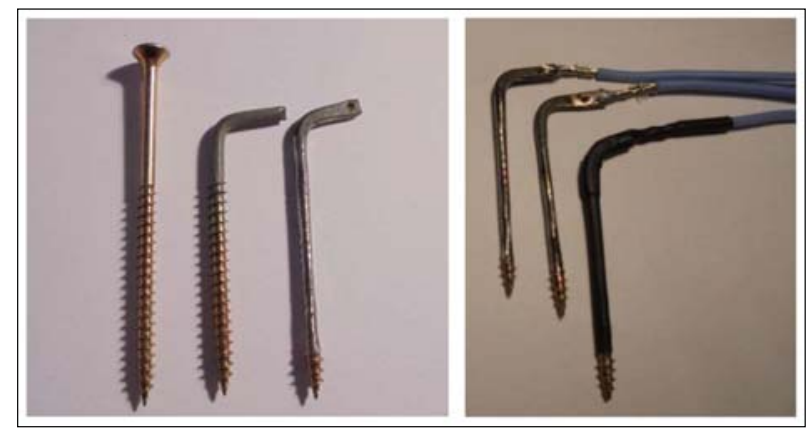

Fig. 3. Manufacturing process of depth probes

\subsection{Probes development}

Two kinds of probes have been designed for the moisture measurement of wooden elements (one of them for measurement immediately underneath the surface and another one for measurement in the centre of wooden elements).

Probes were designed to be better embeddable into the wood elements and also with a goal of a longterm durability (several years). Detailed description of the probe development is described in [4] and manufacturing process is presented in Figs 2 and 3.

The local temperature of the wood was measured at the monitored points by PT 1000 sensors for applying correct thermal correction. Air temperature and relative humidity in the roof structure were measured by HYT 221 sensors. Both types of sensors are produced by IST AG.

\subsection{Analysed detail}

The experimental measurements take place in DEK Experimental Research and Innovation Centre, kept by Stavebniny DEK a.s., located in Brno, Czech Republic. There were preformed several construction variants of the above mentioned details in two different roof structures as is shown in floor plan in Fig. 4.

In the case of structure S1.1 vapour open underlay Dekten Multi-Pro II was used, manufactured from nonwoven polyester fabrics and polymeric layer on the face side of the foil. The overlaps of this foil are glued with a self-adhesive tape. The equivalent diffusion resistance value of this foil is $0.2 \mathrm{~m}$. Underlay of structure S1.4 was performed from bitumen sheet Topdek Cover-Pro. This sheet is made from SBS mod- 


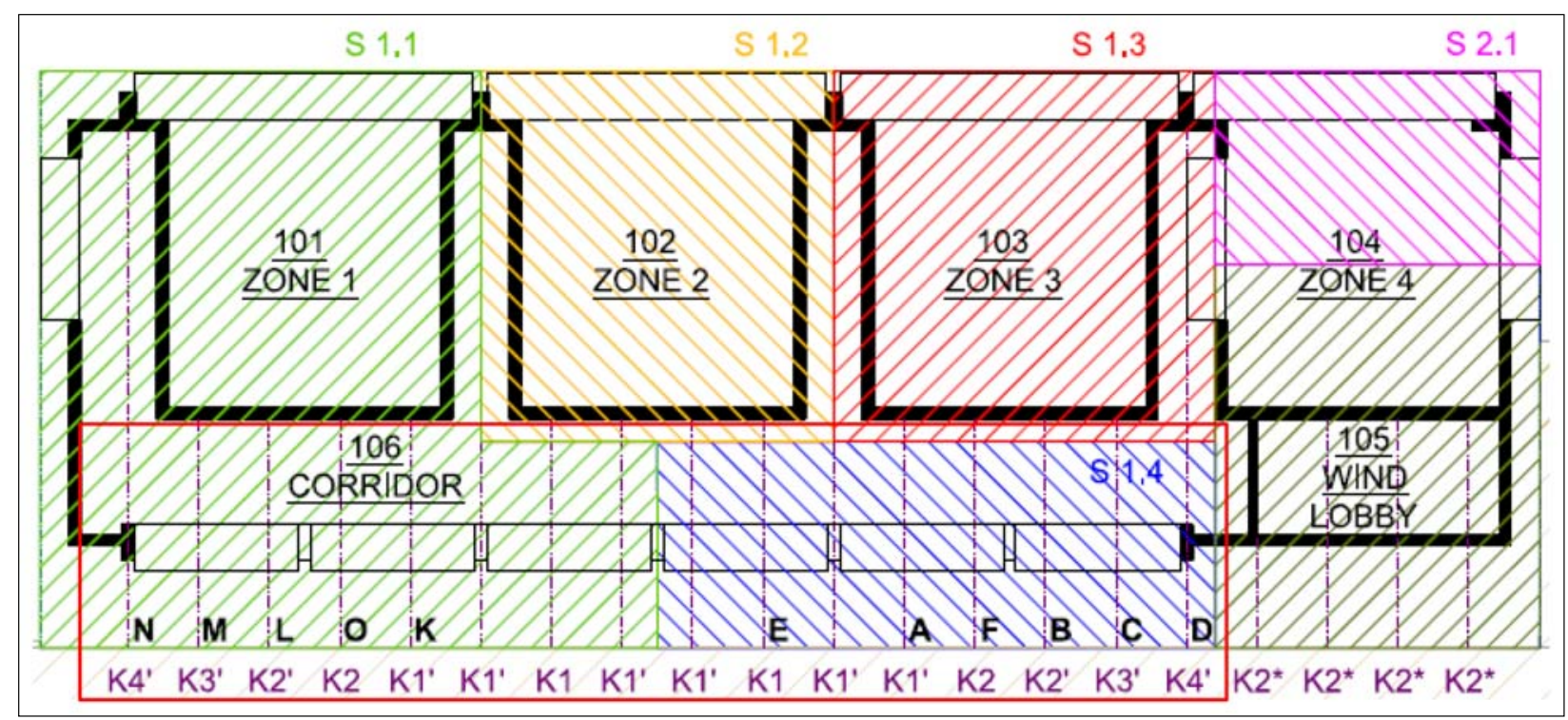

Fig. 4. Floor plan of experimental building - measured part of roof with roof overhang is in red marked zone. There are two roof compositions with different kinds of underlay - S1.1 a S1.4

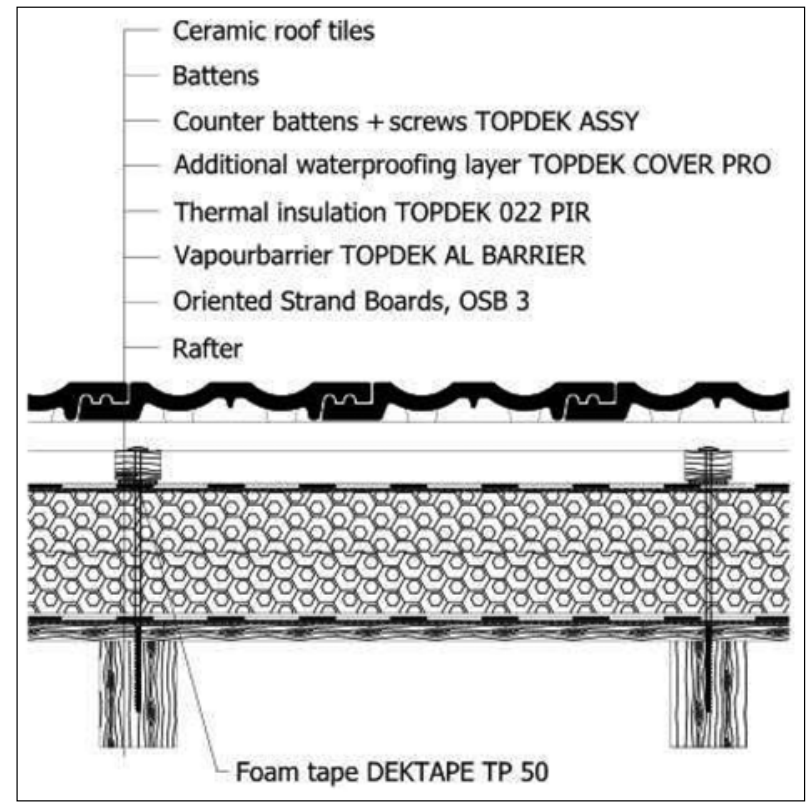

Fig. 5. Roof composition S 1.4

ified bitumen and the polyester carrier mat with a basis weight of $120 \mathrm{~g} / \mathrm{m}^{2}$. The equivalent diffusion resistance value of Topdek cover-pro is $50 \mathrm{~m}( \pm 5 \mathrm{~m})$, that is significantly higher than in structure S1.1 and therefore more risky from vapour condensation point of view. Measurement results from the structure S1.4 are presented in this article. Complete roof structure S1.4 is shown in Fig. 5.

\section{Measurement results}

Examined points were selected in each wooden element for monitoring the temperature and moisture of wood. Installed sensors can be seen in Fig. 6 .

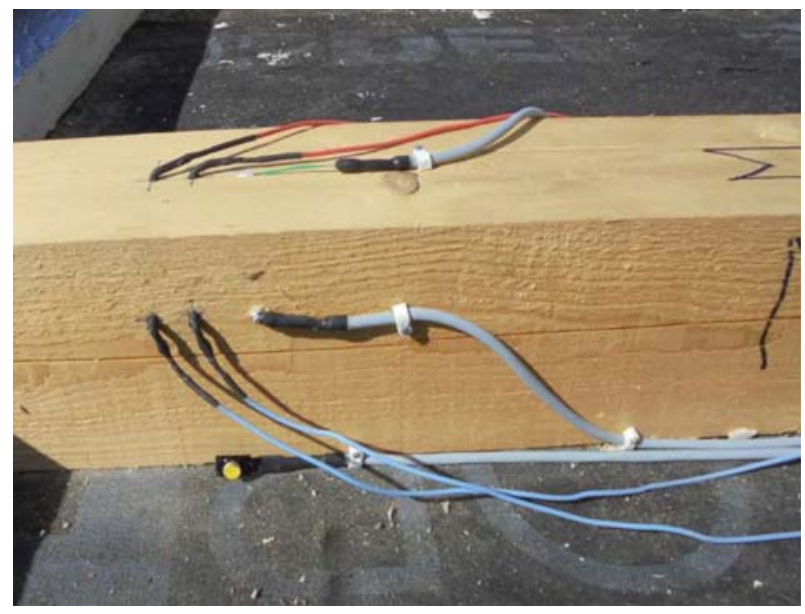

Fig. 6. Installed probes for measuring both depth and surface wood moisture completed with temperature sensors for correct temperature compensation

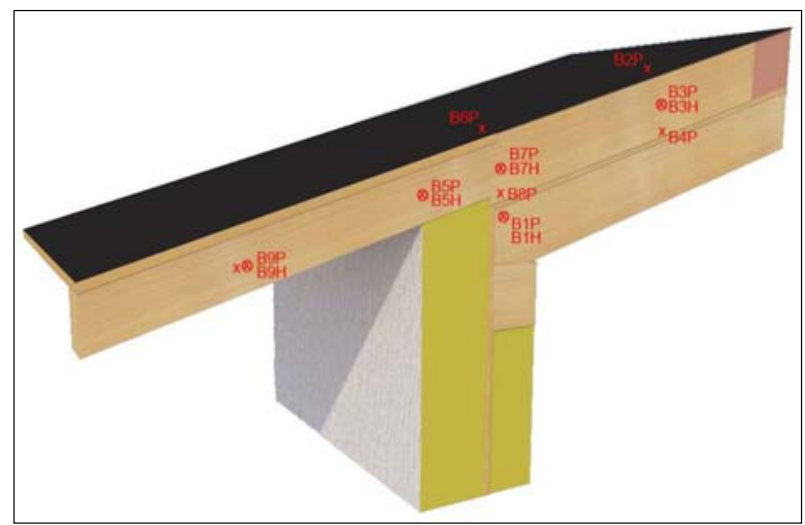

Fig. 7. Construction variant $\mathrm{K} 2$ - rafter ends on a wall plate, roof overhang is created by eaves support of equal height as thermal insulation thickness 


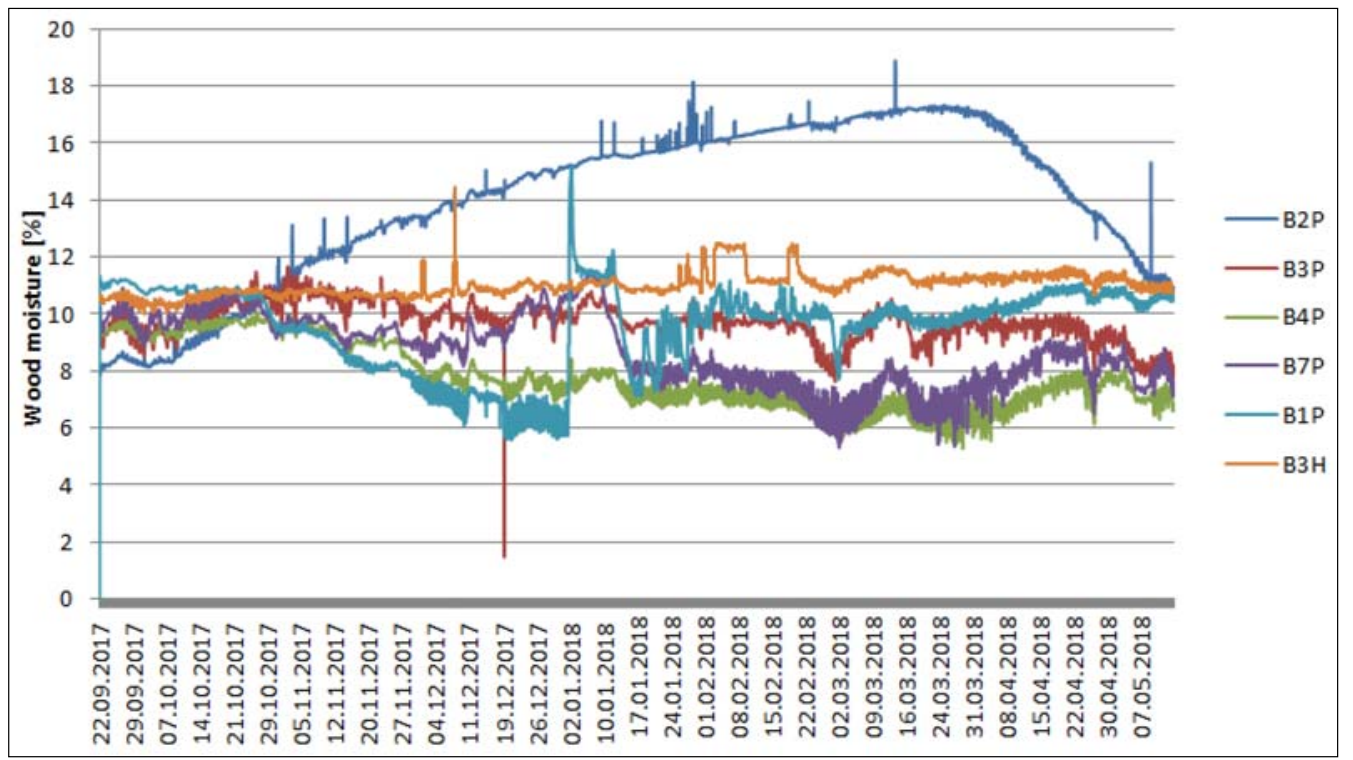

Fig. 8. Wood moisture in monitored points in element of construction variant $\mathrm{K} 2$

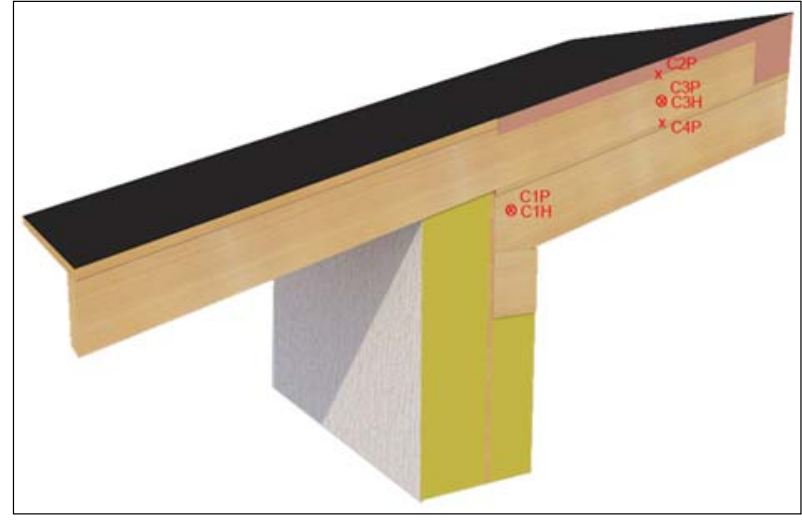

Fig. 9. Construction variant $\mathrm{K} 3$ - rafter ends on a wall plate, roof overhang is created by eaves support, which is cover by $40 \mathrm{~mm}$ of thermal insulation
There were tested four design variants of overlapping the roof. Two most frequently performed variants (marked as K2 and K3) are presented in this paper. Both selected placement of measured points and the difference between these variants are presented in Fig. 7 and Fig. 9. The difference lies in the fact that the wooden element creating the eave overlap in the variant K3 is covered by $40 \mathrm{~mm}$ of PIR insulation unlike variant $\mathrm{K} 2$, where the wooden element is as high as thermal insulation thickness so it is in contact with underlay.

The results of measured wood moisture in monitored points are presented in Fig. 8 and Fig. 10. The measurement took place in the period from 23rd September, 2017 to 7 th May, 2018. The boundary con-

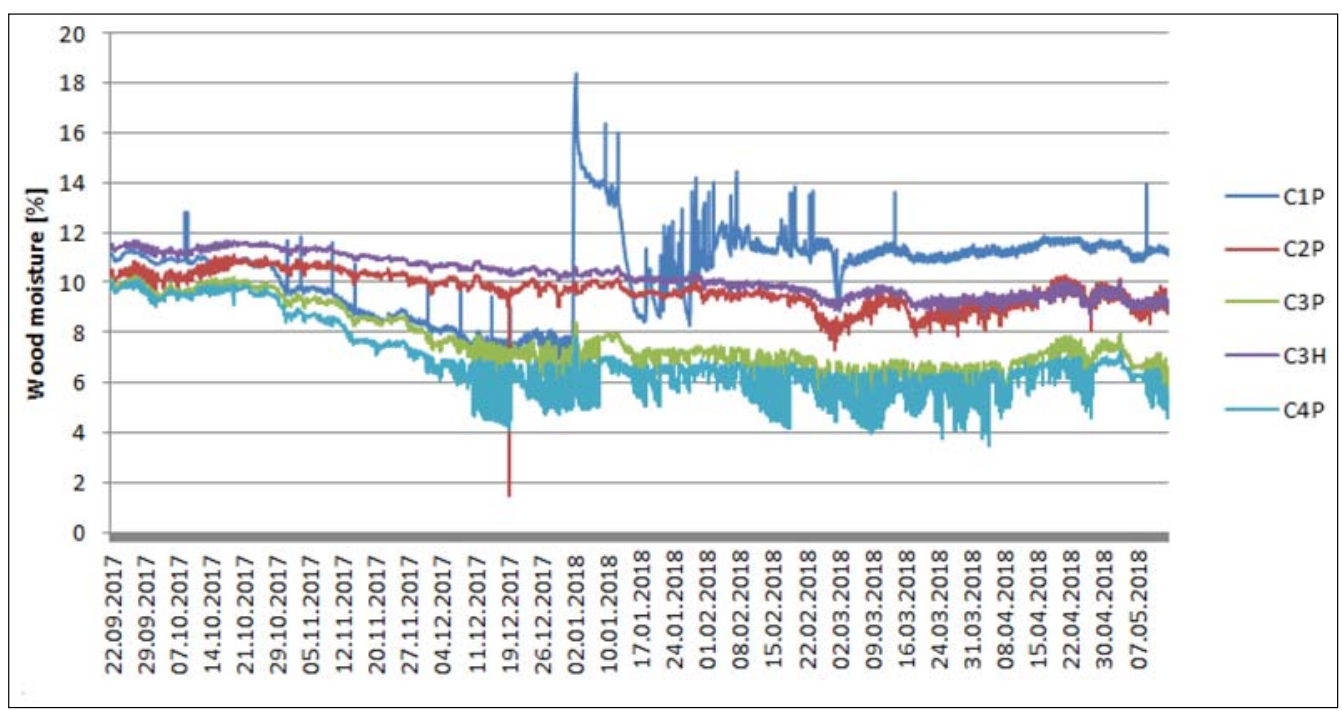

Fig. 10. Wood moisture in monitored points in element of construction variant K3 


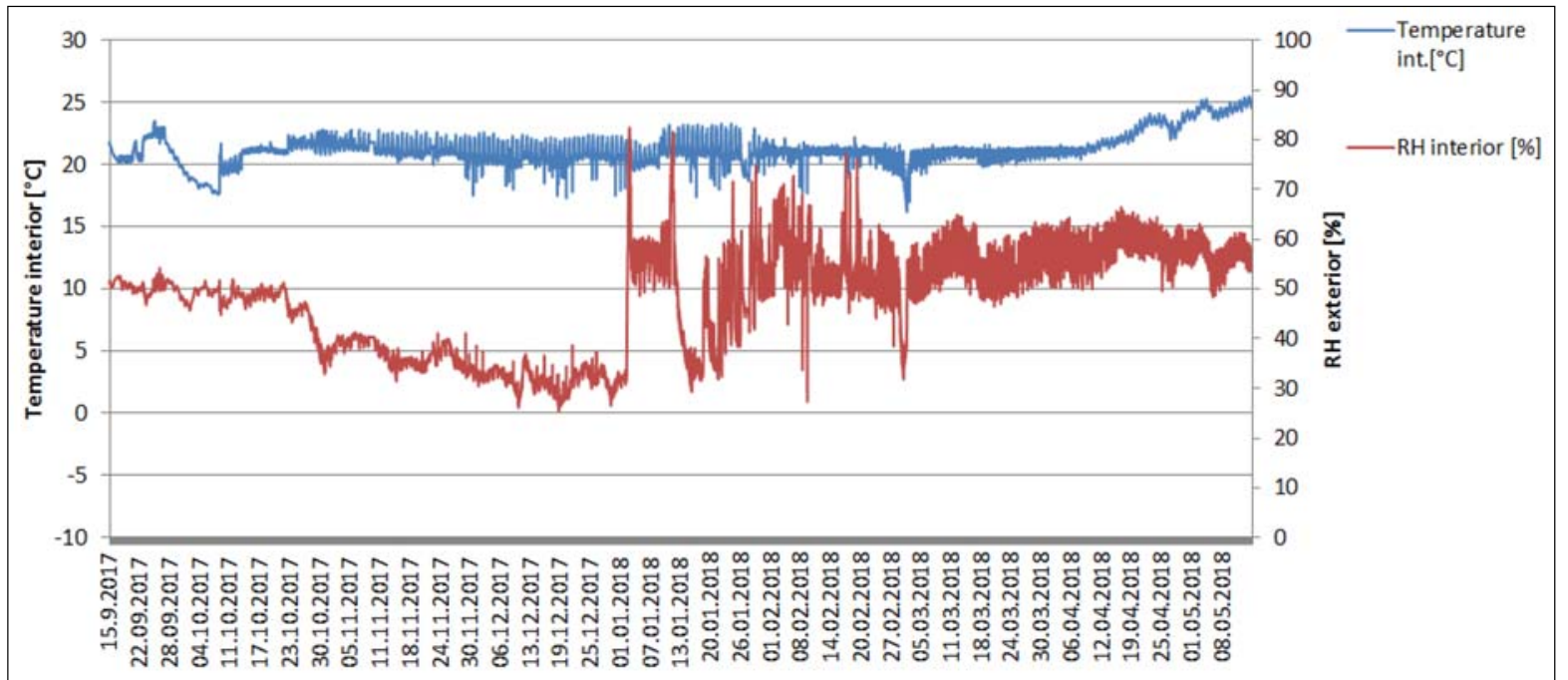

Fig. 11. Indoor air temperature and relative humidity

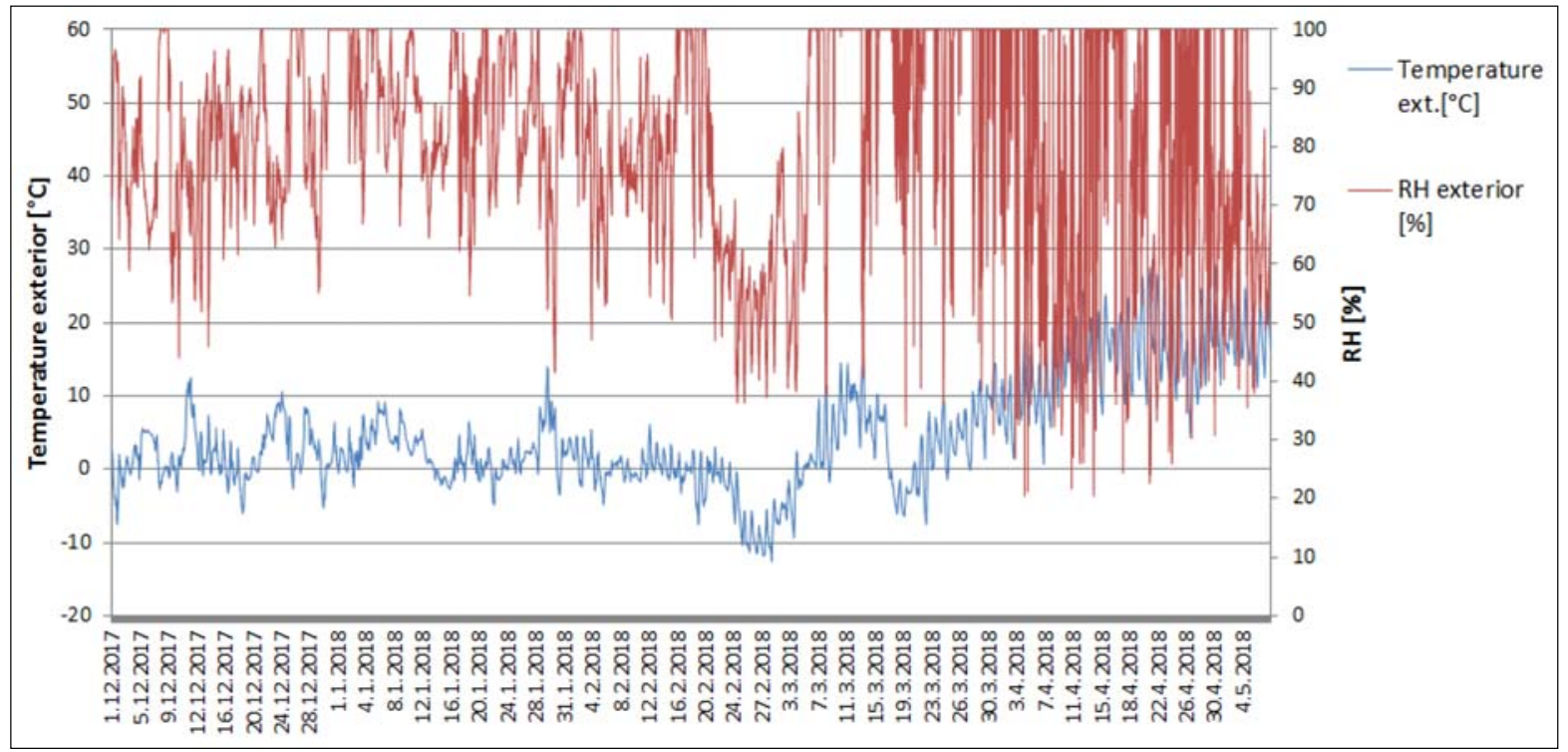

Fig. 12. Outdoor air temperature and relative humidity

ditions, whether interior or exterior, can be seen in Fig. 11 and Fig. 12.

\section{Discussion}

The exceeding safe limits of moisture content in wooden elements could result in the wood being attacked by wood decaying fungi or insects. The moisture content of $18 \%$ is considered as a safe moisture limit. This topic is described e.g. in $[5,6]$.

In the case of construction variant $\mathrm{K} 2$, the measured wood moisture was almost approaching the critical limit at the site below the underlay. The measured values reached $17.2 \%$ in this point. It cannot be ruled out with $100 \%$ certainty that under certain conditions the moisture content of the wooden elements could not be higher than the safe value. These conditions could for example be extreme weather condition or high amount of built-in water during the construction.

According to obtained data, it seems to be safer to use the construction variant $\mathrm{K} 3$, where the highest values of measured wood moisture in the roof structure were below $12 \%$. There was a problem with the using of the $\mathrm{K} 3$ variant in the past due to the low roof structure thicknesses. Requirements for roof insulation are much more stringent nowadays, so there is not any limitation for using the K3 variant.

\section{Conclusion}

The values of moisture content of wood at the monitored points of the elements creating eave overhang 
with above-rafter thermal insulation application were determined. It has been shown that even when the elements are built into the structure between the layers with relatively high equivalent diffusion resistance, safe limits of critical humidity have not been exceeded during the winter. However, the measurements showed that by covering the wooden element with a layer of thermal insulation, the moisture state of this element will be significantly improved. The maximum measured moisture content at the site below the underlay was less than $12 \%$ in the element covered by thermal isolation, while in the non-covered variant it exceeded $17 \%$.

\section{Acknowledgements}

This paper has been worked out under the project FAST-J-15-2909 supported by Ministry of Education, Youth and Sports under "Specific University Research" and thanks to company Stavebniny DEK a.s.

\section{References}

[1] Hartley J., Marchant J. (1995), Methods of Determining the Moisture Content of Wood, Research Division State Forests of New South Wales, Sydney.

[2] Brischke C., Rapp A. O., Bayerbach R. (2008), Measurement system for long-term recording of wood moisture content with internal conductively glued electrodes. Building and Environment, 43, 1566-1574.

[3] Fredriksson M. (2010), Methods for determination of moisture conditions in wood exposed to high moisture levels. Licentiate thesis, Lund Institute of Technology, Sweden.

[4] Soudek P. (2016), Moisture Monitoring of Built-In Wooden Elements, article in Applied Mechanics and Materials, ISSN 1662-7482, Trans. Tech. Publications, Switzerland.

[5] ČSN 73 0540-2 (2011), Thermal protection of building Part 2: Requirements. Praha: Úřad pro technickou normalizaci, metrologii a státní zkušebnictví.

[6] Nielsen K. F., Holm G., Uttrup L. P., Nielsen P. A. (2004), Mould growth on building materials under low water activities - Influence of humidity and temperature on fungi growth and secondary metabolism. International Biodeterioration \& Biodegradation, 54, 325-336. 